\title{
Eight challenges faced by general practitioners caring for patients after an acute coronary syndrome
}

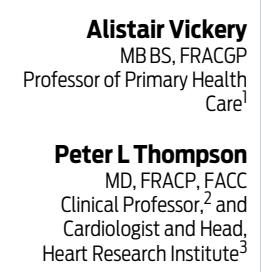

1 School of Primary, Aboriginal, and Rural Health Care, University of Western Australia, Perth, WA.

2 School of Medicine and Pharmacology, University of Western Australia, Perth, WA.

3 Sir Charles Gairdner Hospital, Perth, WA.

peterlthompson@ health.wa.gov.au

doi: 10.5694/mjal4.01250
G eneral practitioners have an essential role in the management of patients who have recently been discharged from hospital after an acute coronary syndrome (ACS). As the duration of hospital stay has shortened over recent decades, this role has become even more important. There are many challenges facing the GP in fulfilling this demanding role. This article deals with eight common challenges faced by the GP caring for patients after an ACS.

\section{Not enough information from the hospital}

Insufficient documentation ranks as one of the major gripes of GPs dealing with hospitals. It is a worldwide problem, and not limited to ACS, although arguably of greater consequence in this potentially unpredictable and life-threatening condition. The discharge summary is the most important and often the only form of communication from hospitals to primary care. An Australian study in 2001 showed that only $37 \%$ of hospital discharge summaries reached the GP. ${ }^{1}$ Audits of discharge summaries in Victorian hospitals found high completion rates within hospital records (88\%-100\%) but significant delays in sending them to GPs (only $4 \%-32 \%$ within 14 days), with fewer than a third available to GPs at the first post-discharge visit. ${ }^{2}$ Quality improvement initiatives can improve these rates - a recent national audit as part of quality improvement showed that $77 \%$ of GPs reported receiving a discharge summary for patients with ACS at a median time of 3 days (range, $0-41$ days) after discharge. ${ }^{3}$ The addition of electronic discharge summaries from hospitals in Australia has improved timeliness, with 83\% of GPs receiving them within 2 weeks from hospitals with such a service. ${ }^{4}$

It is essential that the discharge summary from the hospital conveys the information necessary for the GP to manage the patient's condition after hospital. The list of medications with proof of benefit is quite large, and the ACS patient may be taking an additional four or five new medications at discharge from hospital. The antithrombotic regimen varies according to whether the patient received conservative management, insertion of a baremetal stent, or insertion of a drug-eluting stent in hospital.

The patient may be confused about the purpose of their medications or be unconvinced of their benefit, a setting ripe for non-adherence. There is clear evidence that non-adherence to evidence-based medications can have highly adverse effects on outcome after an ACS. ${ }^{5} \mathrm{~A}$ clear-cut management plan has been shown to improve adherence and to improve outcomes. ${ }^{6}$ This is recommended by the National Heart Foundation of Australia ${ }^{7}$ and should be considered as part of an overall effort to improve risk factor reduction, adherence to medications and improvement of outcomes. ${ }^{8}$ A timely hospital

\section{Summary \\ The general practitioner is essential in the management of the patient who has recently been discharged from hospital following an acute coronary syndrome (ACS), particularly as duration of hospital stay is shorter than in previous decades.}

GPs caring for patients after an ACS face numerous challenges. Often, the first of these is insufficient or delayed documentation from the discharging hospital, although electronic discharge summaries are alleviating this problem.

Post-ACS patients often have comorbidities, and GPs play a key role in managing these. Patients taking dual antiplatelet therapy who need surgery, and post-ACS patients with atrial fibrillation, require particular care from GPs.

Patients will often approach their GP for advice on the safety of other drugs, such as smoking cessation medication, and phosphodiesterase type 5 inhibitors for erectile dysfunction.

For patients complaining of persistent lethargy after an ACS, GPs must consider several differential diagnoses, including depression, hypotension, hypovolaemia, and side effects of $\beta$-blockers.

GPs play an important ongoing role in ensuring that target cholesterol levels are reached with statin therapy; this includes ensuring long-term adherence. They may also need to advise patients who want to stop statin therapy, usually due to perceived side effects.

Many of these challenges can be met with improved and respectful communication between the hospital, the treating cardiologist and the GP.

The patient needs to be closely involved in the decisionmaking process, particularly when balancing the risks of bleeding versus thrombosis.

summary that includes this basic information avoids the patient and the GP wasting valuable time obtaining the information.

\section{The patient is taking dual antiplatelet therapy} and needs surgery

The patient who needs surgery during the 12 months after an ACS or insertion of a drug-eluting stent presents a particular challenge. In the stented patient, there is concern about the risk of stent thrombosis, and this is reduced with dual antiplatelet therapy (DAPT; ie, aspirin with a $\mathrm{P}_{2} \mathrm{Y}_{12}$ inhibitor such as clopidogrel, ticagrelor or prasugrel). ${ }^{9}$ Drug-eluting stents significantly reduce the risk of restenosis at the site of the stent, but require a longer period of DAPT than bare-metal stents to allow for re-endothelialisation of the coronary artery lesion. ${ }^{10}$ As a result, international guidelines recommend $1-3$ months of DAPT for patients who have received a bare-metal stent and 12 months of DAPT for patients who have received a 
drug-eluting stent, with strict adherence to these guidelines recommended. ${ }^{11}$ Some cardiologists prefer a longer course of DAPT if there has been a complex percutaneous coronary intervention or if there is evidence of previous stent thrombosis. There are recent challenges to the recommendations, which have now been in place for more than 5 years and were based on data from older stents. ${ }^{12} \mathrm{~A}$ recent meta-analysis of more modern drug-eluting stent technology shows that 6 months of treatment compared with 12 months reduces the risk of bleeding without any adverse effect on stent thrombosis. ${ }^{13}$

For the patient requiring surgery while taking DAPT, close communication between the surgeon, cardiologist and GP is essential. The risk of thrombosis versus the risk of bleeding needs to be carefully assessed for each case. ${ }^{14}$ Some types of minor surgery (eg, removal of superficial skin lesions) can be undertaken while maintaining DAPT. Most surgical procedures can be conducted safely with the patient maintained on aspirin alone. For higher risk procedures, such as neurosurgical or neurovascular procedures, bridging with an alternative rapidly acting antiplatelet regimen using a glycoprotein IIb/IIIa inhibitor may be recommended. ${ }^{15}$

For those who have been managed conservatively, the relatively high risk of recurrence and the proven efficacy of DAPT ${ }^{16}$ has led to the current recommendation that DAPT remain for 12 months. ${ }^{17}$ As these patients have not received a coronary stent, their risk of coronary thrombosis may be lower, particularly after the first few months. The patient needs to be apprised of the risks and engaged in the decision-making process.

\section{The post-ACS patient with atrial fibrillation}

Atrial fibrillation (AF) commonly coexists with coronary heart disease, or may occur after ACS. ${ }^{18}$ The antithrombotic regimen for the post-ACS patient targets atherothrombosis, and DAPT is mandated for 12 months after ACS for most patients (see above). The risk of stroke is a concern in patients with AF, with an annual risk of $5 \%$, two to seven times that of people without AF. ${ }^{19}$ Aspirin, clopidogrel or DAPT have not been shown to be protective against the risk of stroke in $\mathrm{AF}^{20}$ and anticoagulation with warfarin or a novel oral anticoagulant is recommended in all AF guidelines for patients at risk of stroke, as determined by their $\mathrm{CHA}_{2} \mathrm{DS}_{2}$-VASc (congestive heart failure, hypertension, age $\geqslant 75$ years, diabetes mellitus, stroke, vascular disease, age 65 to 74 years, sex) score. ${ }^{21,22}$ Therefore, most post-ACS patients with AF require triple antithrombotic therapy with a combination of an oral anticoagulant and DAPT. This nearly doubles the risk of bleeding compared with warfarin monotherapy, so the patient requires careful monitoring. ${ }^{23}$

Recent studies have looked at shortening the duration of DAPT with newer stents, ${ }^{13}$ or withdrawing one of the antiplatelet agents. A trial in post-stented patients with AF that compared the effect of triple antithrombotic therapy (aspirin, clopidogrel and warfarin) with that of double antithrombotic therapy (clopidogrel and warfarin) showed no adverse effects with stroke or coronary thrombosis and a substantial reduction in bleeding. ${ }^{24}$ Similar results were seen in the "real world" of a large Danish registry study. ${ }^{25}$ While this is not definitive evidence, it suggests that it may be possible to withdraw aspirin after a few weeks of triple antithrombotic therapy and continue with warfarin and clopidogrel. There are no clinical trials or observational studies to guide therapy in patients taking the new oral anticoagulants or with newer antiplatelet agents such as ticagrelor, and such studies are urgently needed.

\section{The patient wants to consider smoking cessation medication}

Smoking cessation is essential after an ACS. Although it is true that there have not been controlled clinical trials to confirm the benefits of cessation of smoking after an ACS, there are ample observational studies to show that continuation of smoking leads to greatly increased risk of death and recurrence of myocardial infarction, ${ }^{26}$ and cessation can reduce the risk by about a third. ${ }^{27}$ While unassisted cessation is the most effective method, ${ }^{28}$ the reality of clinical practice is that many patients feel they need assistance. A Cochrane review of nicotine replacement therapies (NRTs) in trials involving more than 50000 patients has shown that all the methods of delivery (chewing gum, transdermal patches, oral and nasal sprays, inhalers and tablets/lozenges) are effective, at least in the short term, in assisting quitting, with $50 \%-70 \%$ of patients achieving abstinence. ${ }^{29}$

The Cochrane review confirmed that NRTs did not increase the risk of coronary events. Despite this, there are widespread apprehensions among patients ${ }^{30}$ and stop-smoking practitioners ${ }^{31}$ about the safety of NRTs, and this limits their use, effectiveness and adherence. GPs have an important role in reassuring post-ACS patients that these safety concerns are misplaced. ${ }^{32}$

Bupropion is an antidepressant with partial nicotine antagonist properties, and has been extensively evaluated as adjunctive therapy for smoking cessation. It is effective in the short term, and a Cochrane review showed no adverse cardiovascular effects. ${ }^{33}$ Varenicline has similarly been extensively evaluated in clinical trials, and formal analysis shows no adverse cardiovascular or serious psychiatric adverse effects. ${ }^{34}$ A summary of the evidence for NRTs, bupropion and varenicline concluded that combination NRTs and varenicline had the highest rate of cessation and the lowest risk of long-term relapse. ${ }^{35}$ Both varenicline and bupropion have United States Food and Drug Administration (FDA) warnings about the risk of unusual changes in behaviour, with thoughts of suicide or dying in some patients, ${ }^{36}$ but the warning does not refer specifically to cardiovascular risks for either drug. The GP can discuss the use of these smoking cessation drugs with their patients, and can reassure in general terms about the cardiovascular risks, but may conclude that counselling and support may be more appropriate.

\section{The patient complains of persistent lethargy} after ACS

With modern management, the patient who has recovered from an ACS without suffering extensive myocardial damage can usually be expected to return to normal 
activities a week or two after the event. Unusual lethargy continuing after a coronary event can be a major clinical challenge. Depression is a common comorbidity and an important factor indicating a poor prognosis, ${ }^{37}$ and should be actively considered in the patient with post-ACS lethargy. The American Heart Association has recently recommended that depression should be elevated to the status of a risk factor for adverse medical outcomes in patients with ACS. However, there is currently no evidence to link causality of depression to ACS, nor that treating depression improves survival from ACS. ${ }^{37}$

Tricyclic antidepressants have well recognised adverse cardiac effects ${ }^{38}$ and should be avoided except in low doses. A multicentre study showed that the selective serotonin reuptake inhibitor (SSRI) sertraline was safe and effective among post-ACS patients ${ }^{39}$ and, subsequently, meta-analysis of the SSRI trials have shown no adverse effect on cardiovascular outcomes. ${ }^{40}$

Drug-induced causes of lethargy should also be considered. With increasing use of potent antiplatelet regimens after ACS, the risk of gastrointestinal bleeding has increased, and this may lead to lethargy from irondeficiency anaemia. The negative chronotropic effect of $\beta$-blockers may also contribute. There is ongoing debate about the ideal duration of $\beta$-blockers after ACS, but in the patient who has recovered well with no left ventricular dysfunction or angina, it may be possible to taper off the $\beta$-blocker without adverse effect. ${ }^{41}$

Hypotension and hypovolaemia are also common in the early post-hospital phase of ACS management. This may be due to unnecessary continuation of diuretics or over-enthusiastic dosing with angiotensin-converting enzyme (ACE) inhibitors. This is easily recognised and its early management can lead to a dramatic improvement in wellbeing. If the patient is free of symptoms of cardiac failure and there is no left ventricular dysfunction on echocardiography, there is no benefit in continuing diuretic therapy. Reduction of the dose of ACE inhibitor may be very helpful for the patient with lethargy from persistent hypotension. Of course, the patient may be lethargic because of cardiac failure, and it is important to check left ventricular function with an echocardiogram or by measuring B-type natriuretic peptide to rule out this possibility.

\section{The patient wants to stop statin therapy}

Statins have been extensively studied, and a detailed meta-analysis of 170000 participants in 26 statin trials has shown them to be very effective and safe in most patients, with a $21 \%-22 \%$ relative risk reduction in cardiovascular disease events per $1 \mathrm{mmol} / \mathrm{L}$ reduction in low-density lipoprotein cholesterol (LDL-C) levels over 5 years. ${ }^{42}$ The evidence is so persuasive that most authoritative bodies now recommend that statins of moderate to high intensity be prescribed after ACS irrespective of the cholesterol level. ${ }^{43}$

However, there has been a lot of publicity in Australia about the side effects of statins. Some of the reporting has been alarmist and irresponsible, ${ }^{44}$ and many patients are confused about this issue. The highlighting in 2012 by the US FDA of possible cognitive dysfunction was a major concern for many patients. ${ }^{45}$ The FDA's advice was widely promulgated despite meta-analysis of all studies from 1986 to 2012 showing no evidence of increase in dementia or Alzheimer disease. ${ }^{46,47}$ The meta-analysis cited above showed no sign of an increase in cancer. ${ }^{46}$

An increase in the risk of rhabdomyolysis is the main serious side effect that has been shown with statins in controlled trials. This is exceedingly rare, occurring in about one patient per million prescriptions. ${ }^{48}$ It is dependent on the type of statin, with a higher rate from high-dose simvastatin than atorvastatin among post-ACS patients. ${ }^{49,50}$ On the other hand, myalgia, with or without marginal elevation of creatine kinase, is common and may occur in about $10 \%$ of patients. ${ }^{51}$ Recent reports of an increase in diabetes ${ }^{52}$ are further cause for concern with some patients, but it is important to point out that a statin is one of the most effective treatments for lipid management in established diabetes. ${ }^{53}$

For the patient who is unconvinced by the overwhelming scientific data, a trial of a lower dose or a change in statin may be helpful. If the patient insists on a trial of alternative "natural" cholesterol-lowering drugs, this should be monitored with cholesterol levels if possible. A dramatic increase in total cholesterol or LDL-C level with alternative therapies may be sufficient to persuade the patient to continue with statin therapy. An agreement with the patient that a period of several weeks off the statin to assess the effect on muscle soreness or mental agility may demonstrate that the "side effects" are related to either normal sensations or other causes, rather than a drug side effect.

Among patients who have proven side effects, the use of an alternative LDL-C-lowering agent, such as ezetimibe, cholestyramine or newer experimental agents, may need to be considered. Ezetimibe can effectively lower LDL-C levels, but the benefit of this on outcomes is yet to be established. ${ }^{54}$ Nicotinic acid has not been shown to be effective. $^{55}$

Dietary management has shown reductions in LDL-C levels. About $2 \mathrm{~g} /$ day of plant stanols and sterols has been shown to reduce LDL-C levels by about $10 \%,{ }^{56}$ and the addition of fish oils in those who cannot take statins may show statistically significant reductions in adverse outcomes, despite conflicting recent meta-analyses. ${ }^{57}$ This dietary management for reduction in LDL-C levels can be additive to a low-fat diet and cholesterol-lowering medication.

\section{The patient has not reached the target level with statin therapy}

The target LDL-C level for post-ACS patients was set at $<1.8 \mathrm{mmol} / \mathrm{L}$ after the Pravastatin or Atorvastatin Evaluation and Infection Therapy-Thrombolysis in Myocardial Infarction 22 (PROVE IT - TIMI 22) study. ${ }^{49}$ This demonstrated that a high-intensity statin was more effective than a moderate-intensity statin. The median LDL-C level achieved during treatment in the high-intensity (atorvastatin $80 \mathrm{mg}$ ) group was $62 \mathrm{mg} / \mathrm{dL}$ $(1.60 \mathrm{mmol} / \mathrm{L})$ and in the moderate-intensity (pravastatin $40 \mathrm{mg}$ ) group was $95 \mathrm{mg} / \mathrm{dL}(2.46 \mathrm{mmol} / \mathrm{L})$. The outcome was to set the US target level for post-ACS patients to 
below $70 \mathrm{mg} / \mathrm{dL}(1.8 \mathrm{mmol} / \mathrm{L}){ }^{58}$ and Australia followed suit on this. ${ }^{59}$

A recent revision of the US guidelines has recognised that the target levels were never tested in clinical trials and are based on an extrapolation of the clinical trial evidence. ${ }^{45}$ These new revised guidelines recommend high-intensity statin therapy (defined as a daily dose that lowers LDL-C by $\geqslant 50 \%$ ) rather than moderateintensity statin therapy (lowering LDL-C by $30 \%$ to $<50 \%$ ). High-intensity statins available on the Australian Pharmaceutical Benefits Scheme are atorvastatin 40$80 \mathrm{mg}$ and rosuvastatin $20-40 \mathrm{mg}$.

The GP's role is to check that the patient is taking one of these drugs at the correct dose. If there is persistent elevation of the LDL-C level, a careful check on adherence may be needed. Statin adherence rates overall in Australia are low, with a community-wide study in 2011 showing $43 \%$ of patients discontinued statin within 6 months, $23 \%$ failed to collect their first repeat prescription at 1 month, and a median persistence of 11 months. ${ }^{60}$ If adherence has been confirmed, a higher dose of statin could be considered (eg, an increase of atorvastatin from 40 to $80 \mathrm{mg} /$ day, or rosuvastatin from 20 to $40 \mathrm{mg} /$ day). The addition of ezetimibe or another lipid-lowering agent to a statin has been shown to further lower LDL-C levels, but there is no current evidence of a benefit on cardiovascular outcomes. ${ }^{61}$

\section{The patient seeks advice on erectile} dysfunction and the safety of PDE5 inhibitors

People with coronary heart disease have a risk of erectile dysfunction because of the associated endothelial dysfunction, ${ }^{62}$ and possibly the effect of some cardiovascular drugs. ${ }^{63}$ While men are notoriously reluctant to seek advice on erectile dysfunction, it may be an indicator of worsened cardiovascular risk and the GP needs to be alert to subtle clues to indicate evidence of erectile dysfunction and encourage discussion. ${ }^{64}$ Adjustment of medications (such as reduction of $\beta$-blockers and diuretics) ${ }^{65}$ and reduction of cardiovascular risk factors may be helpful. ${ }^{66}$

Usually, however, use of phosphodiesterase type 5 (PDE5) inhibitors may need to be considered. ${ }^{67}$ There are multiple studies to confirm the overall safety of PDE5 inhibitors in patients with cardiovascular disease, ${ }^{68}$ although the longstanding caution that they must not be used in conjunction with nitrates remains valid. ${ }^{69}$ The GP must check the post-hospital medications to ensure that nitrates in any form (isosorbide mononitrate, nitrate patches, nicorandil) are not being taken by the patient, and that glyceryl trinitrate spray is not used within 24 hours of sildenafil or vardenafil administration or within 48 hours of tadalafil administration. ${ }^{64}$ Choice of PDE5 inhibitor is a matter of preference. A recent metaanalysis concluded the safety profile of each of the agents was similar. ${ }^{70}$ The use of low-dose daily tadalafil has been explored as an alternative to intermittent use, with some success and a good safety profile. ${ }^{71}$ The patient's partner may express concern about "strain on the heart" of enhanced sexual activity with successful use of a PDE5 inhibitor, but the information that the absolute risk increase for myocardial infarction associated with 1 hour of sexual activity per week is estimated to be only 2 to 3 per 10000 person-years may be of some reassurance. ${ }^{72}$

\section{Conclusion}

Of these eight challenges, most can be managed with improved communication between the hospital, the treating cardiologist and the GP. A team approach is essential to deliver effective evidence-based care. When balancing risks (for instance, bleeding versus thrombotic risk), the patient needs to be fully engaged in the decision making.

Competing interests: Peter Thompson has received research funding from AstraZeneca, Boehringer Ingelheim, Pfizer, Bristol-Myers Squibb and Amgen and advisory board fees from AstraZeneca and Pfizer.

Provenance: Commissioned; externally peer reviewed.

1 Wilson S, Ruscoe W, Chapman M, Miller R. General practitioner-hospital communications: a review of discharge summaries. J Qual Clin Pract 2001; 21: 104-108.

2 Belleli E, Naccarella L, Pirotta M. Communication at the interface between hospitals and primary care - a general practice audit of hospital discharge summaries. Aust Fam Physician 2013; 42: 886-890.

3 Wai A, Pulver LK, Oliver K, Thompson A. Current discharge management of acute coronary syndromes: baseline results from a national quality improvement initiative. Intern Med J 2012; 42: e53-e59.

4 Alderton M, Callen J. Are general practitioners satisfied with electronic discharge summaries? HIM J 2007; 36: 7-12.

5 Ho PM, Spertus JA, Masoudi FA, et al. Impact of medication therapy discontinuation on mortality after myocardial infarction. Arch Intern Med 2006; 166: 1842-1847.

6 Clark AM, Hartling L, Vandermeer B, McAlister FA. Meta-analysis: secondary prevention programs for patients with coronary artery disease. Ann Intern Med 2005; 143: 659-672.

7 National Heart Foundation of Australia and the Cardiac Society of Australia and New Zealand. Reducing risk in heart disease 2007: guidelines for preventing cardiovascular events in people with coronary heart disease (updated 2008). Canberra: NHFA, 2008. http://www. heartfoundation.org.au/SiteCollectionDocuments/Reducing-risk-heartdisease-fullguidelines.pdf (accessed Sep 2014).

8 Brieger DB, Redfern J. Contemporary themes in acute coronary syndrome management: from acute illness to secondary prevention. Med J Aust 2013; 199: 174-178.

9 Lüscher TF, Steffel J, Eberli FR, et al. Drug-eluting stent and coronary thrombosis: biological mechanisms and clinical implications. Circulation 2007; 115: 1051-1058.

10 Otsuka F, Finn AV, Yazdani SK, et al. The importance of the endothelium in atherothrombosis and coronary stenting. Nat Rev Cardiol 2012; 9: 439-453.

11 Grines CL, Bonow RO, Casey DE Jr, et al. Prevention of premature discontinuation of dual antiplatelet therapy in patients with coronary artery stents: a science advisory from the American Heart Association, American College of Cardiology, Society for Cardiovascular Angiography and Interventions, American College of Surgeons, and American Dental Association, with representation from the American College of Physicians. Circulation 2007; 115: 813-818.

12 Palmerini T, Biondi-Zoccai G, Della Riva D, et al. Stent thrombosis with drug-eluting stents: is the paradigm shifting? J Am Coll Cardiol 2013; 62: 1915-1921.

13 El-Hayek G, Messerli F, Bangalore S, et al. Meta-analysis of randomized clinical trials comparing short-term versus long-term dual antiplatelet therapy following drug-eluting stents. Am J Cardiol 2014; 114: 236-242.

14 Rossini R, Musumeci G, Visconti LO, et al. Perioperative management of antiplatelet therapy in patients with coronary stents undergoing cardiac and non-cardiac surgery: a consensus document from Italian cardiological, surgical and anaesthesiological societies. Eurolntervention 2014; 10: 38-46

15 Huang PH, Croce KJ, Bhatt DL, Resnic FS. Recommendations for management of antiplatelet therapy in patients undergoing elective noncardiac surgery after coronary stent implantation. Crit Pathw Cardiol 2012; 11: 177-185.

16 Yusuf S, Zhao F, Mehta SR, et al; Clopidogrel in Unstable Angina to Prevent Recurrent Events Trial Investigators. Effects of clopidogrel in addition to aspirin in patients with acute coronary syndromes without ST-segment elevation. NEngl J Med 2001; 345: 494-502. 
17 Brieger D, Kelly AM, Aroney C, et al; National Heart Foundation ACS Implementation and Advocacy Working Group. Acute coronary syndromes: consensus recommendations for translating knowledge into action. Med J Aust 2009; 191: 334-338.

18 Go AS, Mozaffarian D, Roger VL, et al; American Heart Association Statistics Committee and Stroke Statistics Subcommittee. Heart disease and stroke statistics - 2013 update: a report from the American Heart Association. Circulation 2013; 127: e6-e245.

19 Wolf PA, Abbott RD, Kannel WB. Atrial fibrillation as an independent risk factor for stroke: the Framingham Study. Stroke 1991; 22: 983-988.

20 Hart RG, Pearce LA, Aguilar Ml. Meta-analysis: antithrombotic therapy to prevent stroke in patients who have nonvalvular atrial fibrillation. Ann Intern Med 2007; 146: 857-867.

21 Camm AJ, Lip GY, De Caterina R, et al; ESC Committee for Practice Guidelines (CPG). 2012 focused update of the ESC Guidelines for the management of atrial fibrillation: an update of the 2010 ESC Guidelines for the management of atrial fibrillation. Developed with the special contribution of the European Heart Rhythm Association. Eur Heart J 2012; 33: 2719-2747.

22 January CT, Wann LS, Alpert JS, et al. 2014 AHA/ACC/HRS Guideline for the Management of Patients With Atrial Fibrillation: a Report of the American College of Cardiology/ American Heart Association Task Force on Practice Guidelines and the Heart Rhythm Society. J Am Coll Cardiol 2014; Mar 28 [Epub ahead of print].

23 Lamberts M, Gislason GH, Lip GY, et al. Antiplatelet therapy for stable coronary artery disease in atrial fibrillation patients taking an oral anticoagulant: a nationwide cohort study. Circulation 2014; 129: 1577-1585.

24 Dewilde WJ, Oirbans T, Verheugt FW, et al; WOEST study investigators. Use of clopidogrel with or without aspirin in patients taking oral anticoagulant therapy and undergoing percutaneous coronary intervention: an open-label, randomised, controlled trial. Lancet 2013; 381: 1107-1115.

25 Lamberts M, Gislason GH, Olesen JB, et al. Oral anticoagulation and antiplatelets in atrial fibrillation patients after myocardial infarction and coronary intervention. J Am Coll Cardiol 2013; 62: 981-989.

26 Shen L, Peterson ED, Li S, et al. The association between smoking and long-term outcomes after non-ST-segment elevation myocardial infarction in older patients. Am Heart J 2013; 166: 1056-1062.

27 Critchley JA, Capewell S. Mortality risk reduction associated with smoking cessation in patients with coronary heart disease: a systematic review. JAMA 2003; 290: 86-97.

28 Chapman S, Wakefield MA. Large-scale unassisted smoking cessation over 50 years: lessons from history for endgame planning in tobacco control. Tob Control 2013; 22 Suppl 1: i33-i35.

29 Stead LF, Perera R, Bullen C, et al. Nicotine replacement therapy for smoking cessation. Cochrane Database Syst Rev 2012; (11): CD000146.

30 Shiffman S, Ferguson SG, Rohay J, Gitchell JG. Perceived safety and efficacy of nicotine replacement therapies among US smokers and ex-smokers: relationship with use and compliance. Addiction 2008; 103: 1371-1378.

31 Beard E, McDermott M, McEwen A, West R. Beliefs of stop smoking practitioners in United Kingdom on the use of nicotine replacement therapy for smoking reduction. Nicotine Tob Res 2012; 14: 639-647.

32 Mendelsohn C. Optimising nicotine replacement therapy in clinical practice. Aust Fam Physician 2013; 42: 305-309.

33 Cahill K, Stevens S, Perera R, Lancaster T. Pharmacological interventions for smoking cessation: an overview and network meta-analysis. Cochrane Database Syst Rev 2013; (5): CD009329.

34 Rigotti NA, Pipe AL, Benowitz NL, et al. Efficacy and safety of varenicline for smoking cessation in patients with cardiovascular disease: a randomized trial. Circulation 2010; 121: 221-229.

35 Cahill K, Stevens S, Lancaster T. Pharmacological treatments for smoking cessation. JAMA 2014; 311: 193-194.

36 United States Food and Drug Administration. FDA: Boxed warning on serious mental health events to be required for Chantix and Zyban [media release]. 1 Jul 2009. http://www.fda.gov/newsevents/newsroom/pressannouncements/ucml70100.htm (accessed May 2014).

37 Lichtman JH, Froelicher ES, Blumenthal JA, et al; American Heart Association Statistics Committee of the Council on Epidemiology and Prevention and the Council on Cardiovascular and Stroke Nursing. Depression as a risk factor for poor prognosis among patients with acute coronary syndrome: systematic review and recommendations: a scientific statement from the American Heart Association. Circulation 2014; 129: 1350-1369.

38 Rosenberg LB, Whang W, Shimbo D, et al. Exposure to tricyclic antidepressants is associated with an increased risk of incident CHD events in a population-based study. Int J Cardiol 2010; 145: 124-125.

39 Glassman AH, O'Connor CM, Califf RM, et al; Sertraline Antidepressant Heart Attack Randomized Trial (SADHEART) Group. Sertraline treatment of major depression in patients with acute Ml or unstable angina. JAMA 2002; 288: 701-709.

40 Pizzi C, Rutjes AW, Costa GM, et al. Meta-analysis of selective serotonin reuptake inhibitors in patients with depression and coronary heart disease. Am J Cardiol 2011; 107: 972-979.

41 Thompson PL. Should $\beta$-blockers still be routine after myocardial infarction? Curr Opin Cardiol 2013; 28: 399-404

42 Cholesterol Treatment Trialists' (CTT) Collaboration, Baigent C, Blackwell L, et al. Efficacy and safety of more intensive lowering of LDL cholesterol: a meta-analysis of data from 170,000 participants in 26 randomised trials. Lancet 2010; 376: 1670-1681.

43 Stone NJ, Robinson J, Lichtenstein AH, et al. 2013 ACC/AHA guideline on the treatment of blood cholesterol to reduce atherosclerotic cardiovascular risk in adults: a report of the American College of Cardiology/American Heart Association Task Force on Practice Guidelines. J Am Coll Cardiol 2014; 63 (25 Pt B): 2889-2934.

44 Heart of the matter. Catalyst Special Edition. ABC1. 7 Nov 2013. http://www.abc.net.au/ catalyst/heartofthematter/default.htm (accessed Sep 2014).

45 Stone NJ, Robinson JG, Lichtenstein AH, et al. 2013 ACC/AHA guideline on the treatment of blood cholesterol to reduce atherosclerotic cardiovascular risk in adults: a report of the American College of Cardiology/American Heart Association Task Force on Practice Guidelines. Circulation 2014; 129 (25 Suppl 2): S1-S45.

46 Richardson K, Schoen M, French B, et al. Statins and cognitive function: a systematic review. Ann Intern Med 2013; 159: 688-697.

47 McGuinness B, O'Hare J, Craig D, et al. Statins for the treatment of dementia. Cochrane Database Syst Rev 2010; (8): CD007514.

48 Chang JT, Staffa JA, Parks M, Green L. Rhabdomyolysis with HMG-CoA reductase inhibitors and gemfibrozil combination therapy. Pharmacoepidemiol Drug Saf 2004; 13: 417-426.

49 Cannon CP, Braunwald E, McCabe CH, et al; Pravastatin or Atorvastatin Evaluation and Infection Therapy-Thrombolysis in Myocardial Infarction 22 Investigators. Intensive versus moderate lipid lowering with statins after acute coronary syndromes. N Engl J Med 2004; 350: 1495-1504

50 de Lemos JA, Blazing MA, Wiviott SD, et al. Early intensive vs a delayed conservative simvastatin strategy in patients with acute coronary syndromes: phase $Z$ of the $A$ to $Z$ trial. JAMA 2004; 292: 1307-1316.

51 Thompson PD, Clarkson P, Karas RH. Statin-associated myopathy. JAMA 2003; 289: $1681-1690$.

52 Navarese EP, Buffon A, Andreotti F, et al. Meta-analysis of impact of different types and doses of statins on new-onset diabetes mellitus. Am J Cardiol 2013; 111: 1123-1130.

53 de Vries FM, Denig P, Pouwels KB, et al. Primary prevention of major cardiovascular and cerebrovascular events with statins in diabetic patients: a meta-analysis. Drugs 2012; 72 2365-2373.

54 Blazing MA, Giugliano RP, Cannon CP, et al. Evaluating cardiovascular event reduction with ezetimibe as an adjunct to simvastatin in 18,144 patients after acute coronary syndromes: final baseline characteristics of the IMPROVE-IT study population. Am Heart J 2014; 168 : 205-212.

55 AIM-HIGH Investigators, Boden WE, Probstfield JL, et al. Niacin in patients with low HDL cholesterol levels receiving intensive statin therapy. N Engl J Med 2011; 365: 2255-2267.

56 Katan MB, Grundy SM, Jones P, et al. Efficacy and safety of plant stanols and sterols in the management of blood cholesterol levels. Mayo Clin Proc 2003; 78: 965-978.

57 Rizos EC, Ntzani EE, Bika E, et al. Association between omega-3 fatty acid supplementation and risk of major cardiovascular disease events: a systematic review and meta-analysis. JAMA 2012; 308: 1024-1033.

58 National Heart, Lung, and Blood Institute. Third Report of the Expert Panel on Detection, Evaluation, and Treatment of the High Blood Cholesterol in Adults (Adult Treatment Pane III): executive summary. 2001. https://www.nhlbi.nih.gov/guidelines/cholesterol/atp_iii. htm (accessed Jun 2014)

59 Tonkin A, Barter P, Best J, et al. National Heart Foundation of Australia and the Cardiac Society of Australia and New Zealand: position statement on lipid management - 2005 Heart Lung Circ 2005; 14: 275-291.

60 Simons LA, Ortiz M, Calcino G. Long term persistence with statin therapy -- experience in Australia 2006-2010. Aust Fam Physician 2011; 40: 319-322.

61 Gudzune KA, Monroe AK, Sharma R, et al. Effectiveness of combination therapy with statin and another lipid-modifying agent compared with intensified statin monotherapy: a systematic review. Ann Intern Med 2014; 160: 468-476.

62 Miner M, Nehra A, Jackson G, et al. All men with vasculogenic erectile dysfunction require a cardiovascular workup. Am J Med 2014; 127: 174-182.

63 Kloner RA, Henderson L. Sexual function in patients with chronic angina pectoris. Am J Cardiol 2013; 111: 1671-1676.

64 Vlachopoulos CV, Terentes-Printzios DG, loakeimidis NK, et al. Prediction of cardiovascula events and all-cause mortality with erectile dysfunction: a systematic review and metaanalysis of cohort studies. Circ Cardiovasc Qual Outcomes 2013; 6: 99-109.

65 Manolis A, Doumas M. Antihypertensive treatment and sexual dysfunction. Curr Hypertens Rep 2012; 14: 285-292.

66 Gupta BP, Murad MH, Clifton MM, et al. The effect of lifestyle modification and cardiovascular risk factor reduction on erectile dysfunction: a systematic review and meta-analysis. Arch Intern Med 2011; 171: 1797-1803.

67 Levine GN, Steinke EE, Bakaeen FG, et al. Sexual activity and cardiovascular disease: a scientific statement from the American Heart Association. Circulation 2012; 125: 1058-1072.

68 Chrysant SG. Effectiveness and safety of phosphodiesterase 5 inhibitors in patients with cardiovascular disease and hypertension. Curr Hypertens Rep 2013; 15: 475-483.

69 Chew KK, Stuckey BG, Thompson PL. Erectile dysfunction, sildenafil and cardiovascular risk. Med J Aust 2000; 172: 279-283.

70 Yuan J, Zhang R, Yang Z, et al. Comparative effectiveness and safety of oral phosphodiesterase type 5 inhibitors for erectile dysfunction: a systematic review and network meta-analysis. Eur Urol 2013; 63: 902-912.

71 Porst H, Giuliano F, Glina S, et al. Evaluation of the efficacy and safety of once-a-day dosing of tadalafil $5 \mathrm{mg}$ and $10 \mathrm{mg}$ in the treatment of erectile dysfunction: results of a multicenter, randomized, double-blind, placebo-controlled trial. Eur Urol 2006; 50 : 351-359.

72 Dahabreh IJ, Paulus JK. Association of episodic physical and sexual activity with triggering of acute cardiac events: systematic review and meta-analysis. JAMA 2011; 305: 1225-1233. 